Article

\title{
Green Synthesis and Incorporation of Sericin Silver Nanoclusters into Electrospun Ultrafine Cellulose Acetate Fibers for Anti-Bacterial Applications
}

\author{
Mujahid Mehdi 1,2®, Huihui Qiu ${ }^{1}$, Bing Dai ${ }^{1}$, Raja Fahad Qureshi ${ }^{2,3}$, Sadam Hussain ${ }^{1,2}$, Muhammad Yousif ${ }^{1}{ }^{1}$, \\ Peng Gao ${ }^{1, *(D)}$ and Zeeshan Khatri ${ }^{2, *(\mathbb{D})}$ \\ 1 National Engineering Laboratory for Modern Silk, College of Textile and Clothing Engineering, \\ Soochow University, Suzhou 215123, China; mujahid11te83@gmail.com (M.M.); \\ kitty.huihui@aliyun.com (H.Q.); db@szdfhj.cn (B.D.); sadam11te75@gmail.com (S.H.); \\ muhammadyousif.te72@gmail.com (M.Y.) \\ 2 Center of Excellence in Nanotechnology and Materials, Mehran University of Engineering and Technology, \\ Jamshoro 76060, Pakistan; raja.ashraf@faculty.muet.edu.pk \\ 3 Department of Textile Engineering, Mehran University of Engineering and Technology, \\ Jamshoro 76060, Pakistan \\ * Correspondence: pgao116@126.com (P.G.); zeeshan.khatri@faculty.muet.edu.pk (Z.K.); \\ Tel.: +86-15862320382 (P.G.); +92-(0)22-2772250 (Z.K.)
}

check for

updates

Citation: Mehdi, M.; Qiu, H.; Dai, B.; Qureshi, R.F.; Hussain, S.; Yousif, M.; Gao, P.; Khatri, Z. Green Synthesis and Incorporation of Sericin Silver Nanoclusters into Electrospun Ultrafine Cellulose Acetate Fibers for Anti-Bacterial Applications. Polymers 2021, 13, 1411. https://doi.org/ $10.3390 /$ polym 13091411

Academic Editor: Andrea Ehrmann

Received: 1 April 2021

Accepted: 25 April 2021

Published: 27 April 2021

Publisher's Note: MDPI stays neutral with regard to jurisdictional claims in published maps and institutional affiliations.

Copyright: (c) 2021 by the authors. Licensee MDPI, Basel, Switzerland. This article is an open access article distributed under the terms and conditions of the Creative Commons Attribution (CC BY) license (https:// creativecommons.org/licenses/by/ $4.0 /)$.

\begin{abstract}
Fiber based antibacterial materials have gained an enormous attraction for the researchers in these days. In this study, a novel Sericin Encapsulated Silver Nanoclusters (sericin-AgNCs) were synthesized through single pot and green synthesis route. Subsequently these sericin-AgNCs were incorporated into ultrafine electrospun cellulose acetate (CA) fibers for assessing the antibacterial performance. The physicochemical properties of sericin-AgNCs/CA composite fibers were investigated by transmission electron microscopy (TEM), field emission electron microscopy (FE-SEM), Fourier transform infrared spectroscopy (FTIR) and wide X-ray diffraction (XRD). The antibacterial properties of sericin-AgNCs/CA composite fibers against Escherichia coli (E. coli) and Staphylococcus aureus (S. aureus) were systematically evaluated. The results showed that sericin-AgNCs incorporated in ultrafine CA fibers have played a vital role for antibacterial activity. An amount of $0.17 \mathrm{mg} / \mathrm{mL}$ sericin-AgNCs to CA fibers showed more than $90 \%$ results and elevated upto $>99.9 \%$ with $1.7 \mathrm{mg} / \mathrm{mL}$ of sericin-AgNCs against E. coli. The study indicated that sericin-AgNCs/CA composite confirms an enhanced antibacterial efficiency, which could be used as a promising antibacterial product.
\end{abstract}

Keywords: silver nanoclusters; sericin; cellulose acetate; electrospinning; Antibacterial Nanofibers

\section{Introduction}

Globally, a new and emerging variety of infectious diseases have brought the human health under a big threat. In most of the cases, the bacterial infection not only cause severe sickness accompanied by developing viral influenza (such as SARs and avian flu), but these microorganisms can also be spread into the environment making it rather unsafe [1,2]. For this reason, exploring new antimicrobial agents have gained much attention in past few decades. Generally, the metallic nanoparticles ( $\mathrm{Ag}, \mathrm{Au}, \mathrm{Cu}$, and $\mathrm{Pt}$ ) and metallic oxides nanoparticles $\left(\mathrm{Ag}_{2} \mathrm{O}, \mathrm{CuO}, \mathrm{ZnO}, \mathrm{TiO}_{2}, \mathrm{Fe}_{2} \mathrm{O}_{3}\right.$, and $\left.\mathrm{SiO}_{2}\right)$ has been reported for antibacterial applications [3]. Amongst these nanoparticles, the silver nanoparticles are notably preferred due to their strong antimicrobial efficiency against microorganisms [4]. It is believed that the bacterial cell can be destroyed upon its the interaction with the Ag ion. The positively charged Ag ions, due to their strong affinity to sulfur proteins, adhere to the cell wall and cytoplasmic membrane [5-7]. This results into the blockage of bacterial respiratory system and demolishing the cell production. Subsequently this leads to the remarkable decline into the growth of further bacteria $[8,9]$. 
In a comparison with Ag particles, Ag ultra-small nanoparticles are improved in chemical stability, heat resistance, release of Ag ions, and durability, which will ultimately bring more opportunities for antimicrobial products [10]. Previous investigations revealed that the size [11], shape [12], surface coating [13], and surface charge [14] of silver ultrasmall nanoparticles can significantly affect antibacterial efficacy. The novel metal (Au, $\mathrm{Ag}, \mathrm{Cu}$, and $\mathrm{Pt}$ ) nanoclusters (NCs) composed of few to hundreds of atoms exhibited ultra-small sizes $(<5 \mathrm{~nm})$ that approach to the fermi wavelength of the conduction electrons. They show discrete energy levels, resulting in obvious fluorescence and molecule-like properties $[15,16]$. Thus, these NCs possess very unique properties than that of traditional metal nanoparticles and have attracted great attraction in recent years. These NCs have been extensively investigated in biolabeling and bioimaging, medicine, catalysis, and nanoelectronics $[17,18]$. Therefore, it is anticipated that silver nanoclusters (AgNCs) may also exhibit superior antimicrobial properties. Recently, Jian-Cheng group has reported the antibacterial performance of ultra-small DHLA-AgNCs and the results showed that silver ions of rich NCs could act as efficient nano reservoirs for antibacterial activity $[19,20]$. Sericin is extracted from silk fiber (Bombyx mori silkworm) and present in the outer layer of silk fiber. Sericin contains 18 types of amino acids, such as serine, glycine, lysine, etc. Sericin is a biocompatible and biodegradable natural biopolymer exhibiting antioxidant, moisture absorption, antibacterial and UV resistance properties [21,22].

Recently, safe and advanced non-woven nanofibrous dressings have received tremendous attention in antibacterial applications [23]. It is also stated that nanofibers have remarkable properties such as high interconnected porosity, large surface area to volume ratios [24,25]. To enhance the stability and therapeutic efficacy, Ag nanoparticles has been incorporated into various polymeric nanofibers including cellulose acetate (CA) [26], polyurethane [27], poly (ethylene oxide) [28], poly (vinyl alcohol) [29], and poly (lactic-coglycolic acid) [30]. While CA contains polysaccharides groups from cellulose materials, it is a commonly used biopolymer and promising material for medical applications. Many conventional metal nanoparticles incorporating into electrospun nanofibers has been prepared. However, there is a considerable need to enhance antibacterial efficiency of electrospun membrane and its biocompatibility. Due to their ultra small size, it is assumed that metal nanoclusters can fulfil the above purpose.

In the present study, sericin mediated silver nanoclusters were prepared and incorporated into ultrafine CA nanofibers in order to assess the antibacterial activity of sericin-AgNCs/CA composite membrane against against $S$. aureus and E. coli. It was found that there is significant effect of sericin-AgNCs on the performance of antibacterial activity due to ultra-small size of Ag particles. The physicochemical properties of sericinAgNCs incorporated into ultrafine CA fibers were examined with transmission electron microscopy (TEM), field emission electron microscopy (FE-SEM), Fourier transform infrared spectroscopy (FTIR) and wide X-ray diffraction (XRD). To the best of our knowledge, sericin-AgNCs were synthesized for the very first time, and incorporated into ultrafine CA fibers for antibacterial application.

\section{Experimental}

\subsection{Materials}

Cellulose acetate $(\mathrm{CA}, 30 \mathrm{KDa})$, Silver Nitrate $\left(\mathrm{AgNO}_{3}, 99.9 \%\right)$, and sericin were purchased from Sigma Aldrich Co., Ltd. (St. Louis, MO, USA). Sodium hydroxide (NaOH, $99 \%)$, Acetone $\left(\mathrm{C}_{3} \mathrm{H}_{6} \mathrm{O}, 99.5 \%\right)$ and Dimethyl formamide $\left(\mathrm{C}_{3} \mathrm{H}_{7} \mathrm{NO}, 99.5 \%\right)$ were purchased from Sinopharm Chemical Reagent Co., Ltd. (Shanghai, China). Ultra-pure water was used during all experiments.

\subsection{Synthesis of Sericin-AuNCs}

The template of $\mathrm{Ag}$ Nanoclusters with sericin was synthesized by using $\mathrm{AgNO}_{3}$ regent. For this, $20 \mathrm{~mL}$ of sericin $(50 \mathrm{mg} / \mathrm{mL})$ and $20 \mathrm{~mL}$ of $\mathrm{AgNO}_{3}(10 \mathrm{mM})$ was prepared separately and both solutions were transferred into an incubator at $37^{\circ} \mathrm{C}$ for $10 \mathrm{~min}$. 
Afterwards, both solutions were mixed together and shaken gently to get a homogenous solution of the mixture. Then, $2 \mathrm{~mL} \mathrm{NaOH}(1 \mathrm{M})$ was added in the mixture and kept on stirring for $3 \mathrm{~min}$. The solution was later incubated at $37^{\circ} \mathrm{C}$ for $16 \mathrm{~h}$ and then placed further for $12 \mathrm{~h}$ into refrigerator at $-20^{\circ} \mathrm{C}$. Finally, the sample was placed for freeze drying for 2 days to achieve Sericin-AgNCs in powder form.

\subsection{Electrospinning}

The ultrafine CA fibers were fabricated according to our previous method [31]. Briefly, the polymer solution consists of $17 \%$ CA polymer was dissolved in acetone: DMF with ratio of 2:1 respectively. Then, different amounts of synthesized sericin-AgNCs powder $(0.17 \mathrm{mg} / \mathrm{mL}, 0.85 \mathrm{mg} / \mathrm{mL}$ and $1.7 \mathrm{mg} / \mathrm{mL})$ was added into the polymeric solution and stirred for $24 \mathrm{~h}$ in order to get homogeneous solution. The prepared solution was filled in a $5 \mathrm{~mL}$ syringe and placed vertically on micro-injection pump (LSP02-1B, Baoding longer precision pump Co., Ltd., Baoding, China). The feed rate for the solution was adjusted at a constant and controllable rate of $0.5 \mathrm{~mL} / \mathrm{h}$. High voltage of $10 \mathrm{kV}$ was applied using power supply (DWP303-1AC, Tianjin Dongwen High Voltage Co., Baoding, China). The distance between needle and collector was set at $15 \mathrm{~cm}$. The fibers were collected on aluminum foil and after collecting fibers, samples were dried in open air for $24 \mathrm{~h}$.

\subsection{Antibacterial Activity}

The antibacterial performance was analyzed using the common shake flask protocol [32]. This protocol is specifically designed for specimen's treatment with non-releasing antibacterial agents under dynamic contact conditions. Escherichia coli (BUU25113) and Staphylococcus aureus (B-sub 168) were cultivated in nutrient broth at $37^{\circ} \mathrm{C}$ for $18 \mathrm{~h}$ and the prepared solution was examined by broth dilution method. The number of viable bacterial cells reached $1 \times 10^{9} \mathrm{cfu} / \mathrm{mL}$. During four times serial dilution with $0.03 \mathrm{~mol} / \mathrm{L}$ PBS, the number of viable bacterial cells is adjusted $3 \times 10^{5} \mathrm{cfu} / \mathrm{mL}$ to $4 \times 10^{3} \mathrm{cfu} / \mathrm{mL}$. After obtaining the desired growth of bacterial cells, $0.05 \mathrm{~g}$ sample (CA fibers) was poured into conical flask containing $65 \mathrm{~mL}$ of $0.3 \mathrm{mM}$ PBS solution and $5 \mathrm{~mL}$ of the prepared solution containing bacterial growth. This mixed up solution was then placed on shaking machine at $37{ }^{\circ} \mathrm{C}$ for $18 \mathrm{~h}$. After shaking, the process was further repeated upto four times for serial dilution by mixing $1 \mathrm{~mL}$ of solution from the flask and $9 \mathrm{~mL}$ of $0.3 \mathrm{mM}$ PBS. Finally $1 \mathrm{~mL}$ of the solution of bacterial growth with different concentration was taken and placed onto an agar plate. After $24 \mathrm{~h}$ of incubation at $37.8^{\circ} \mathrm{C}$, the number of bacterial colonies formed on the agar plates were counted visually. Moreover, the antibacterial performance was established from obtained results and percentage bacterial reduction was calculated according to following equation.

$$
R=\frac{(B-A)}{B} \times 100 \%
$$

where $R$ is the percentage bacterial reduction, $B$ and $A$ are the number of residual colonies of before and after treated with ultrafine CA fibers.

\subsection{Material Analysis}

The surface morphology and average diameter of template sericin-AuNCs were analyzed using transmission electron microscope (TEM, H-800 Hitachi Ltd., Tokyo, Japan) operating at $200 \mathrm{kV}$. The average particle size of sericin Ag NCs was measured from individual particles on the TEM images. Surface morphology of ultrafine electrospun CA fibers and sericin-AgNCs incorporated into ultra-fine CA fibers was measured using Field emission scanning electronic microscopy (FE-SEM, S-4800 Hitachi Ltd., Tokyo, Japan). The average fiber diameter was measured using image J software and graphical presented by counting 50 distinct fibers from FE-SEM images. The SEM samples were sputtered with gold before examination. Chemical composition of sericin-AgNCs incorporated into ultrafine CA fiber was obtained using energy-dispersive X-ray spectroscopy (EDS, S-3000 
N Hitachi Ltd., Tokyo, Japan) elemental analysis, showing carbon, oxygen and silver as the main elements. Fourier transform infrared spectroscopy (FTIR) measurement was analyzed with Thermo Fisher Scientific Inc., Waltham, MA, USA. All the FTIR samples 1-2 mg were ground with $0.1 \mathrm{~g} \mathrm{KBr}$ and pressed into a pellet before testing. Finally, the crystallinity of ultra-fine CA fibers and sericin-AgNCs incorporated into ultra-fine CA fibers were analyzed using X-ray diffraction (XRD) model D/max-IIB, Rigaku. Samples were analyzed in the range of $10-50^{\circ}$ at the scanning speed of $2 \theta=4^{\circ} / \mathrm{min}$. The ultra violet adsorption and fluorescence studies were evaluated using UV-visible spectrophotometer (Shimadzu UV2450, Kyoto, Japan) and UV-visible fluorescence spectrofluorometer (FLS920, Edinburgh, Livingston, UK) respectively.

\section{Results and Discussion}

\subsection{Synthesis of Sericin-AgNCs}

The synthesis of sericin-AgNCs was accomplished through the one pot, green synthesis route. As illustrated in Figure 1, sericin is actually a functional protein created by Bombyx mori (silkworms) in the production of silk, which make up the layers found on top of the fibrin. There are three different types of sericin, including sericin $\mathrm{A}$, sericin $\mathrm{B}$ and sericin C. Due to the disulfide bonds and free cysteine, sericin play an important role in directing the synthesis of AgNCs. In the synthetic process, Ag ions were first introduced into the solution of sericin, where upon some Ag ions interact with the thiol groups of sericin to form functional Ag thiolate intermediates. After reduction, the spatial conformation of protein is further destructed from alkaline condition, followed by the exposure of more thiol site. The phenolic group of $Y$ converts into a negative phenolic ion that can reduce Ag ions to $\mathrm{Ag}$ atoms. Finally, the resultant $\mathrm{Ag}$ atoms aggregate to form $\mathrm{Ag}$ clusters stabilized by the NH groups of the sericin [19].

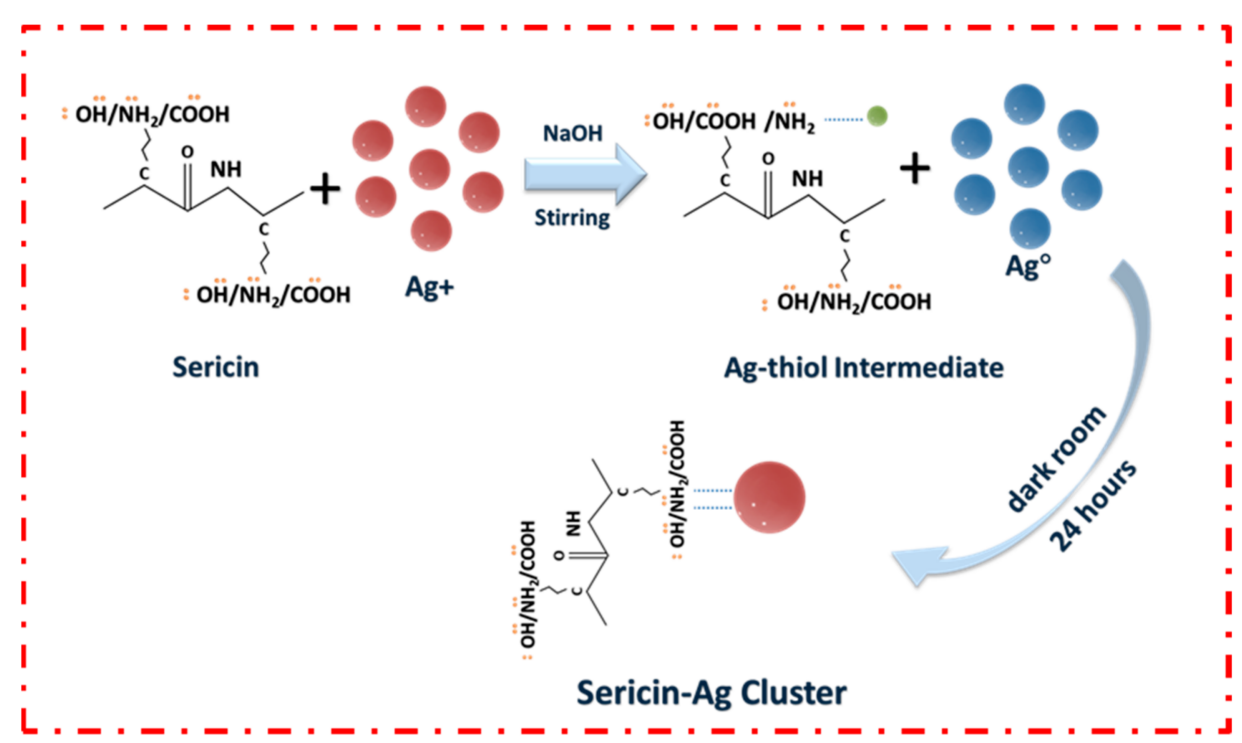

Figure 1. Typical illustration of synthesized sericin-AgNCs.

\subsection{Physico-Chemical Analysis}

The Figure 2A,B shows that sericin-AgNCs had maximum absorbance value at $440 \mathrm{~nm}$ and had fluorescence emission peaks at $500 \mathrm{~nm}$ respectively. Hence, the lyophilized sericin-AgNCs powder maintained the corresponding fluorescence emission. It is worth mentioned that samples were stable in their aqueous solutions and powder at $4{ }^{\circ} \mathrm{C}$ in the dark room for more than 3 months. 

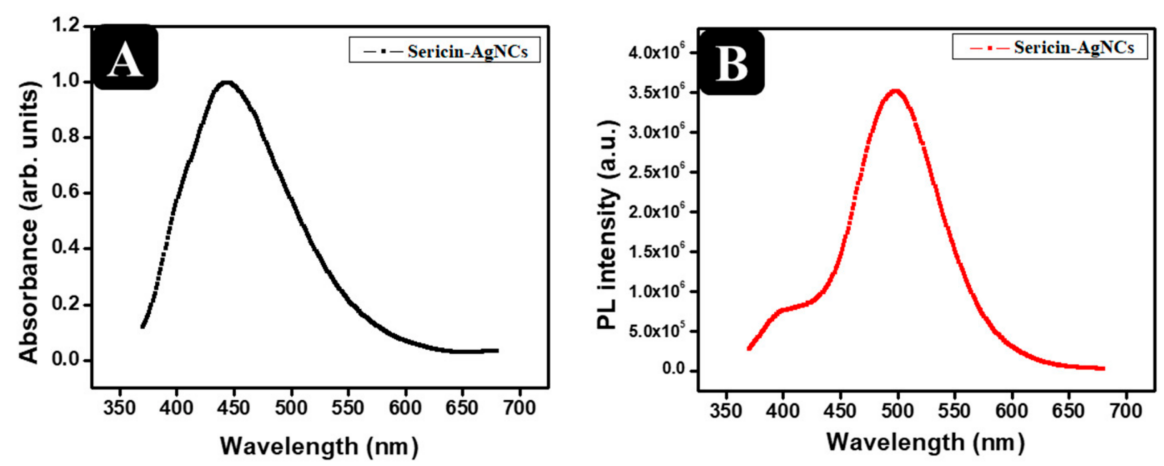

Figure 2. (A) UV-visible spectrum of sericin-AgNCs solution, and (B) UV-fluorescence spectrum of sericin-AgNCs solution.

The TEM technique was performed to assess the surface morphology and measure the size distribution of the sericin-AgNCs. Figure 3A shows the TEM image of sericin-AgNCs in which sericin-AgNCs got quasi-spherical and monodisperse having ultra-small size. Whereas the diameter distribution (Figure 3B) indicates that sericin-AgNCs have an average size of $2.5 \pm 0.5 \mathrm{~nm}$ and obtained diameter distribution is in agreement with Gaussian fitting [9]. Moreover, the SEM images (Figure 3C) of ultrafine CA fibers revealed smooth surface fibrous morphology having average fiber diameter of $300 \mathrm{~nm}$. After incorporation of sericin-AgNCs into ultrafine CA fibers, the surface morphology (Figure 3E) retains its smooth surface fibrous morphology with similar average fiber diameter of $300 \mathrm{~nm}$ due to very less amount of sericin-AgNCs incorporated into CA fibers [33].
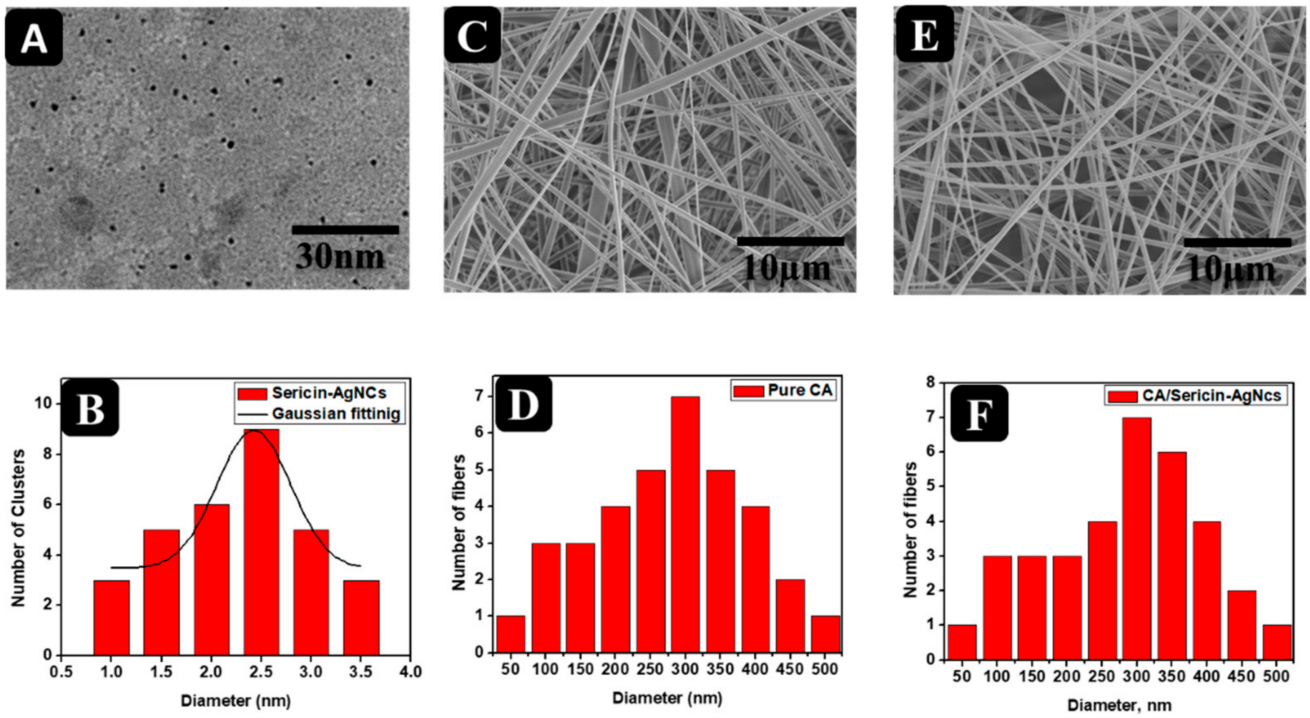

Figure 3. (A) TEM image of sericin-AgNCs, (B) histogram of sericin-AgNCs, (C) SEM images of pure CA fibers, (D) histogram of pure CA fibers, (E) SEM image of sericin-AgNCs incorporated into CA fibers, and (F) histogram of sericin-AgNCs incorporated into CA fibers.

The EDS was performed to confirm the presence of silver clusters in the ultrafine CA fibers after incorporating the sericin-AgNCs. Figure 4 shows the EDS elemental mapping and EDS spectrum of sericin-AgNCs incorporated ultrafine CA fibers. The EDS spectrum confirms the presence of silver clusters with $0.26 \%$ total weight of other components present in CA fibers. While the element mapping shows the uniform presence of silver clusters on the surface of CA fibers [34]. 

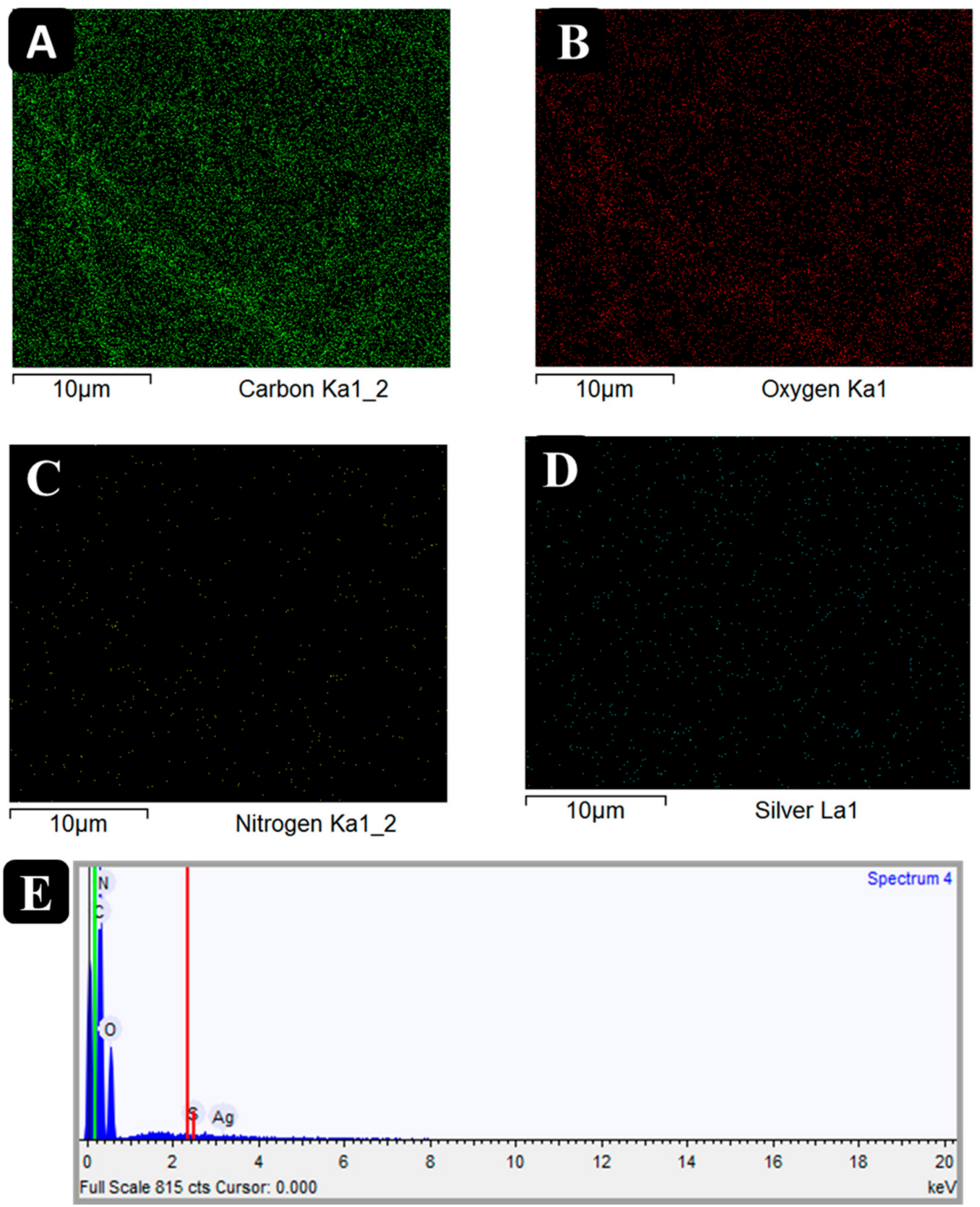

Figure 4. (A-D) EDS elemental mapping of sericin-AgNCs incorporated into ultrafine CA fibers, and (E) EDS spectrum and table (inset) showing the elemental composition of sericin-AgNCs incorporated into ultrafine CA fibers.

Figure 5 indicates XRD spectrum of electrospun CA fibers and incorporated sericinAgNCs with CA fibers. The XRD structure of electrospun CA fibers membrane showed a wide peak at $23.2^{\circ}$, which explains an amorphous structure. While incorporating sericinAgNCs, the diffractions peak shifted to about $20.6^{\circ}$, the comparative peak intensity showed a slightly decreases $[35,36]$. These results ensured the successful incorporation of sericinAgNCs with in the electrospun CA fibers and explained that the AgNCs were actively interacting with the $\mathrm{CA}$ microstructure acting as nuclei sites during the spinning process to induce CA fibers crystallization. 


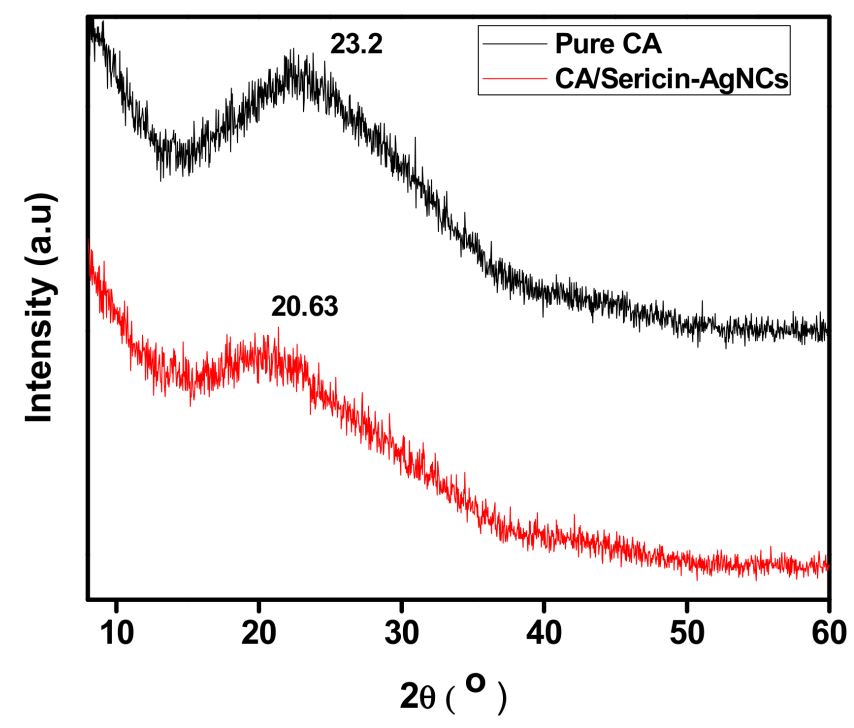

Figure 5. XRD results of pure CA and CA/sericin-AgNCs composite.

FTIR spectrum was used to analyze the chemical variations of electrospun CA fibers after incorporated sericin-AgNCs and confirms the successful hydrolysis of sericin-AgNCs with in the CA fibers. Figure 6 shows the broad spectrum of pure CA fibers and CA fibers with sericin-AgNCs. The pure $C A$ fibers showed main typical peaks at $1745 \mathrm{~cm}^{-1}(C=O)$, $1375 \mathrm{~cm}^{-1}\left(\mathrm{C}_{-} \mathrm{CH}_{3}\right)$ and $1227 \mathrm{~cm}^{-1}(\mathrm{C}-\mathrm{O}-\mathrm{C})$; corresponding to the vibrations of the acetate group of the CA fibers [37]. Furthermore, sericin-AgNCs incorporated into CA fibers showed a wide peak generated at $3345 \mathrm{~cm}^{-1}$ which corresponds the $\mathrm{NH}$ and $\mathrm{OH}$ groups of sericin [38], while the hydroxyl vibration at $3680 \mathrm{~cm}^{-1}$ was slightly decreased. In addition, a weak adsorption was found at $875 \mathrm{~cm}^{-1}$, which corresponded to the silver compound and showed the successful incorporation of sericin-AgNCs into the CA fibers [36].

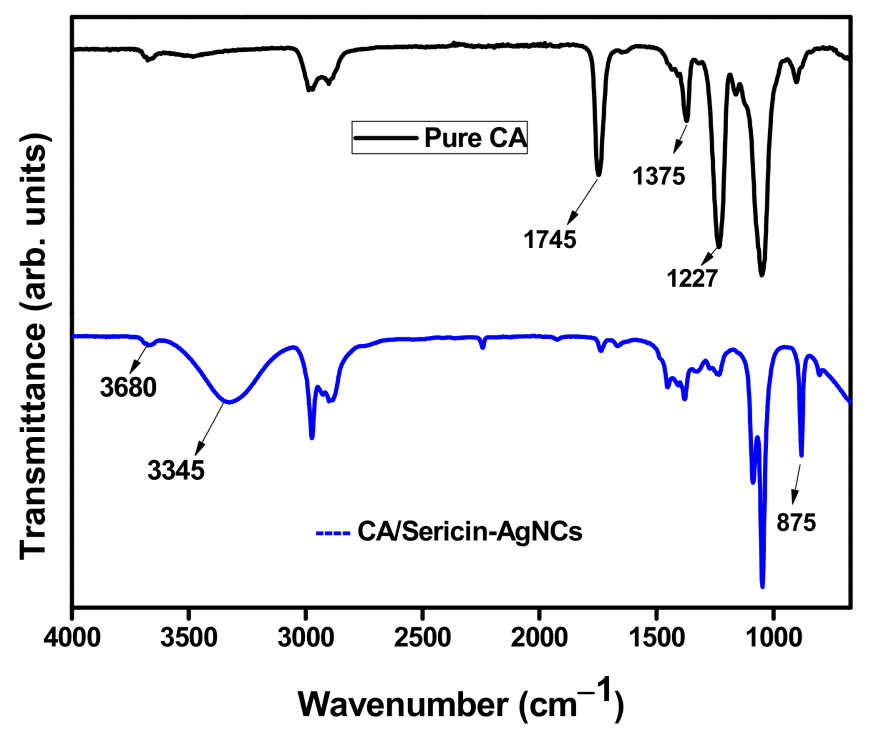

Figure 6. FTIR results of pure CA and sericin-AgNCs/CA fibers and both curves are shifted vertically for clarity.

\subsection{Antibacterial Activity Assessment}

The potential application of antibacterial activity on ultrafine CA fibers incorporated with sericin-AgNCs was examined against E. coli and S. aureus. As prepared electrospun CA fibers without sericin-AgNCs were examined as a control experiment. The bacterial colonies were incubated in a growing medium with the presence of various amount of 
sericin-AgNCs incorporated into ultrafine CA fibers and the antibacterial characteristics of resultant products were examined by standard shake flask protocol. Increasing the amount of sericin-AgNCs into CA fibers showed significant improvement in antibacterial activity. The total density of bacterial colonies for pure CA fibers was very high (Figure 7A,B), and antibacterial activity was observed nearly zero, while the small amount of sericinAgNCs incorporated into CA fibers showed a remarkable improvement against $E$. coli and S. aureus. Although the amount of sericin-AgNCs was only $0.17 \mathrm{mg} / \mathrm{mL}$ ultrafine CA fibers, the antibacterial rate against E. coli and S. aureus could reach more than $85 \%$ antibacterial reduction (Figure 8). Furthermore, the antibacterial effect of sericin-AgNCs mediated ultrafine CA fibers was significantly improved with increase amount of sericinAgNCs. The results indicated that the $1.7 \mathrm{mg} / \mathrm{mL}$ amount of sericin-AgNCs was enough to get more than $99.9 \%$ antibacterial reduction rate (Figure 7A,B). Moreover, the further increased amount of sericin-AgNCs showed similar antibacterial reduction rate with $1.7 \mathrm{mg} / \mathrm{mL}$ sericin-AgNCs and results were calculated in Figure 8. These results suggest that pure CA fiber did not show any antibacterial reduction and it was believed that due to addition of sericin-AgNCs into ultrafine CA fibers was the reason behind of this remarkable antibacterial reduction. Additionally, literature confirms that the antibacterial reduction of any product containing Ag was mainly verified by the total release rate of Ag ions [19]. In present work, due to ultrasmall particle size, the increase of Ag amount will lead a greater number of silver ions to enlargement and increase the total surface area of Ag nanoparticle; hence the release rate of silver ions was enhanced which can ultimately enhance the antibacterial reduction rate using sericin-AgNCs/CA composite. As per our experimental outcomes, it can be summarized that the CA fibers containing $1.7 \mathrm{mg} / \mathrm{mL}$ sericin-AgNCs showed excellent antibacterial reduction rate and amount of $\mathrm{Ag}$ was much lower than used in previous $\mathrm{Ag} /$ composites reports $[5,8,36,38,39]$. While promising characteristics of sericin makes our product very potential against numerous applications including biomedical materials, sports apparatus, and laminating films.

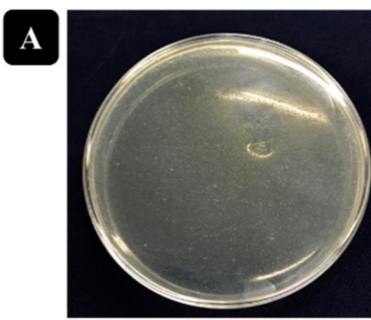

Pure CA Fibers

B

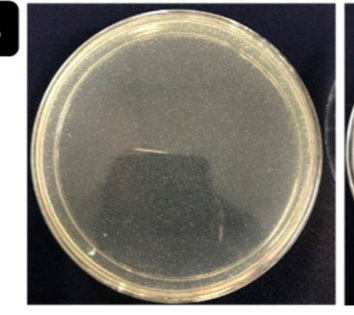

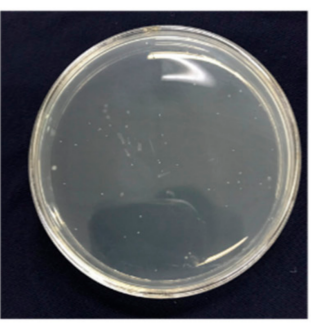

$0.17 \mathrm{mg} / \mathrm{mL}$

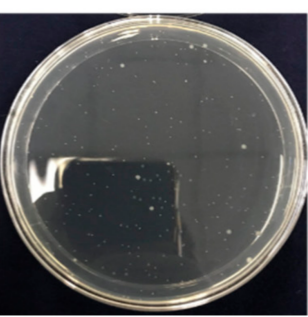

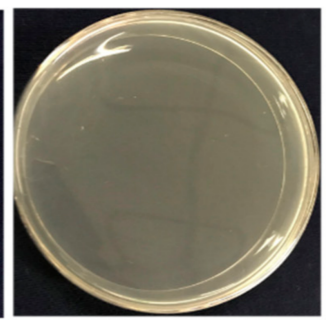

$0.85 \mathrm{mg} / \mathrm{mL}$

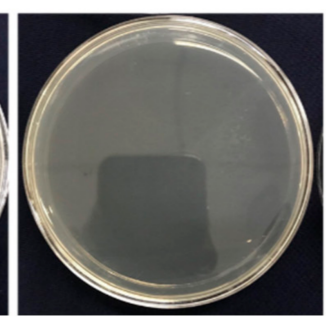

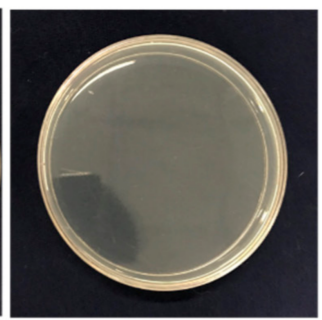

$1.7 \mathrm{mg} / \mathrm{mL}$

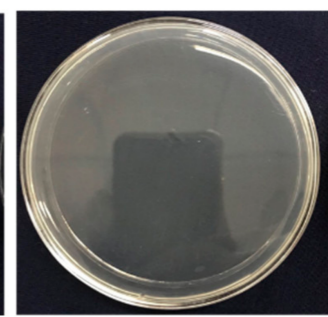

Figure 7. Bacterial colonies in the plates for (A) Escherichia coli and (B) Staphylococcus aureus at different contents of the sericin-AgNCs loaded into ultrafine CA fibers in the nutrient broth. 


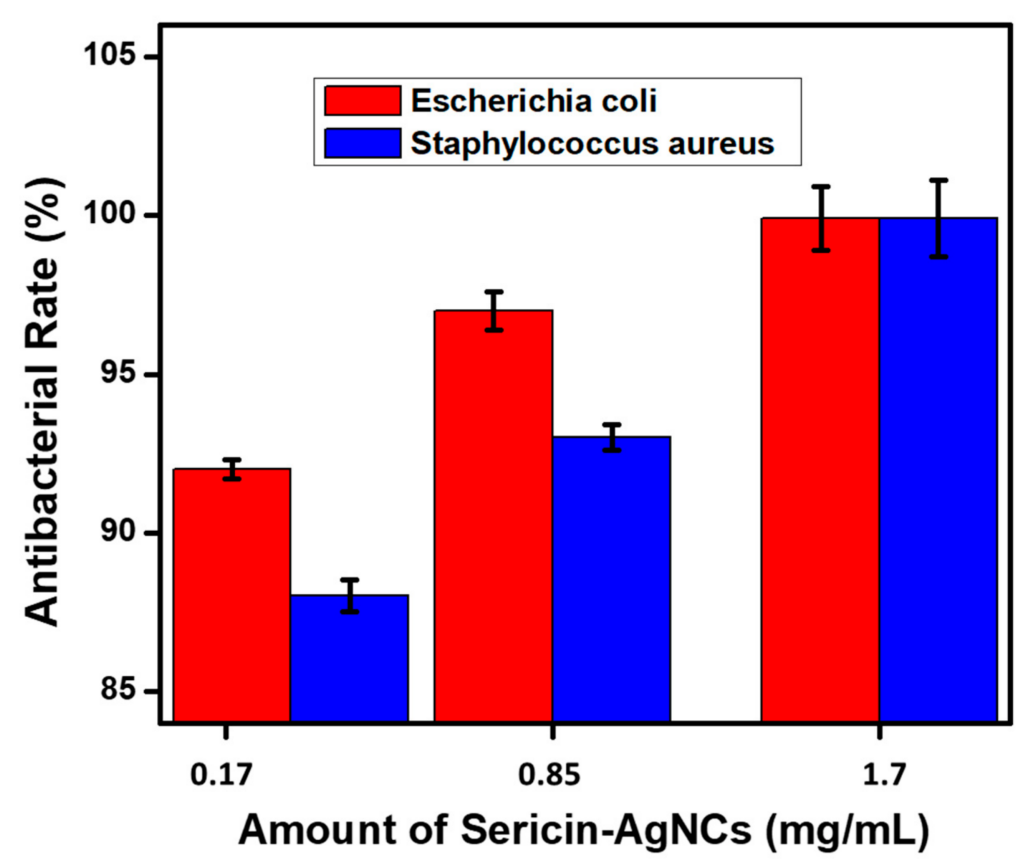

Figure 8. Degree of growth inhibition of different contents of sericin-AgNCs for bacterial suspension against Escherichia coli and Staphylococcus aureus.

It is worth noting that silver nanoclusters compared to other metals were considered safer antimicrobial agents due to their low toxicity. Sericin-AgNCs showed remarkable antibacterial property with ultra low amount of $1.7 \mathrm{mg} / \mathrm{mL}$ and results suggested that sericin-AgNCs incorporated into ultrafine CA fibers can be potential candidate for many biomedical applications including wound healing. To address potential impact of sericinAgNCs, more and more research should be carried out to highlight its side effects on human health and ecology. This will lead to a better understanding and facilitate use of silver nanoclusters on commercial large scale as antimicrobial agents for applications onto different biomedical applications.

\section{Conclusions}

In the present study, a simple green synthesis route for sericin-AgNCs has been introduced and successfully incorporated into ultrafine CA fibers via electrospinning technique in order to report antibacterial properties. The average particle size of sericinAgNCs was measured $2.5 \mathrm{~nm}$ and EDS results exhibited successful incorporation of sericinAgNCs into ultrafine CA fibers. FTIR results confirmed the presence of sericin-AgNCs incorporated within ultrafine CA fibers. The antibacterial activities of sericin-AgNCs mediated ultrafine CA fibers were examined by shake flask method against the E. coli and S. aureus protocols. The results showed that sericin-AgNCs loaded ultrafine CA fibers exhibits outstanding antibacterial properties even with a ultralow content of sericinAgNCs; as inhibition rate attained more than $90 \%$ at $0.17 \mathrm{mg} / \mathrm{mL}$ loading of sericin-AgNCs into ultrafine CA fibers and was finally reached $>99.9 \%$ at $1.7 \mathrm{mg} / \mathrm{mL}$ amount of sericin$\mathrm{AgNCs}$ against $E$. coli and S. aureus. The current results confirmed that the synergistic antibacterial effects of sericin-AgNCs with ultrafine CA fibers, and the composite can be used as promising antibacterial material for further study in biomedical applications.

Author Contributions: Conceptualization, M.M., H.Q. and P.G.; methodology, M.M. and H.Q.; formal analysis, R.F.Q., M.Y. and B.D.; investigation, S.H. and B.D.; writing-original draft preparation, S.H. and P.G.; writing-review and editing, M.M., R.F.Q. and Z.K.; supervision, Z.K. All authors have read and agreed to the published version of the manuscript.

Funding: This research received no external funding. 
Institutional Review Board Statement: Not applicable.

Informed Consent Statement: Not applicable.

Data Availability Statement: The data presented in this study are available on request from the corresponding author.

Acknowledgments: This work was supported by Mehran University of Engineering and Technology Jamshoro, Pakistan and Soochow University, China.

Conflicts of Interest: The authors declare no conflict of interest.

\section{References}

1. Naeimi, A.; Payandeh, M.; Ghara, A.R.; Ghadi, F.E. In vivo evaluation of the wound healing properties of bio-nanofiber chitosan/polyvinyl alcohol incorporating honey and Nepeta dschuparensis. Carbohydr. Polym. 2020, 240, 116315. [CrossRef] [PubMed]

2. Shefa, A.A.; Sultana, T.; Park, M.K.; Lee, S.Y.; Gwon, J.-G.; Lee, B.-T. Curcumin incorporation into an oxidized cellulose nanofiber-polyvinyl alcohol hydrogel system promotes wound healing. Mater. Des. 2020, 186, 108313. [CrossRef]

3. Saratale, R.G.; Ghodake, G.S.; Shinde, S.K.; Cho, S.-K.; Saratale, G.D.; Pugazhendhi, A.; Bharagava, R.N. Photocatalytic activity of $\mathrm{CuO} / \mathrm{Cu}(\mathrm{OH})_{2}$ nanostructures in the degradation of Reactive Green 19A and textile effluent, phytotoxicity studies and their biogenic properties (antibacterial and anticancer). J. Environ. Manag. 2018, 223, 1086-1097. [CrossRef] [PubMed]

4. Saratale, R.G.; Shin, H.-S.; Kumar, G.; Benelli, G.; Ghodake, G.S.; Jiang, Y.Y.; Kim, D.S.; Saratale, G.D. Exploiting fruit byproducts for eco-friendly nanosynthesis: Citrus $\times$ clementina peel extract mediated fabrication of silver nanoparticles with high efficacy against microbial pathogens and rat glial tumor C6 cells. Environ. Sci. Pollut. Res. 2017, 25, 10250-10263. [CrossRef]

5. Matsumura, Y.; Yoshikata, K.; Kunisaki, S.-I.; Tsuchido, T. Mode of Bactericidal Action of Silver Zeolite and Its Comparison with That of Silver Nitrate. Appl. Environ. Microbiol. 2003, 69, 4278-4281. [CrossRef]

6. Saratale, R.G.; Saratale, G.D.; Ghodake, G.; Cho, S.-K.; Kadam, A.; Kumar, G.; Jeon, B.-H.; Pant, D.; Bhatnagar, A.; Shin, H.S. Wheat straw extracted lignin in silver nanoparticles synthesis: Expanding its prophecy towards antineoplastic potency and hydrogen peroxide sensing ability. Int. J. Biol. Macromol. 2019, 128, 391-400. [CrossRef]

7. Abduraimova, A.; Molkenova, A.; Duisembekova, A.; Mulikova, T.; Kanayeva, D.; Atabaev, T. Cetyltrimethylammonium Bromide (CTAB)-Loaded $\mathrm{SiO}_{2}-\mathrm{Ag}$ Mesoporous Nanocomposite as an Efficient Antibacterial Agent. Nanomaterials 2021, 11, 477. [CrossRef]

8. Sheikh, F.A.; Barakat, N.A.M.; Kanjwal, M.A.; Chaudhari, A.A.; Jung, I.-H.; Lee, J.H.; Kim, H.Y. Electrospun antimicrobial polyurethane nanofibers containing silver nanoparticles for biotechnological applications. Macromol. Res. 2009, 17, 688-696. [CrossRef]

9. Saratale, G.D.; Saratale, R.G.; Kim, D.-S.; Kim, D.-Y.; Shin, H.S. Exploiting Fruit Waste Grape Pomace for Silver Nanoparticles Synthesis, Assessing Their Antioxidant, Antidiabetic Potential and Antibacterial Activity Against Human Pathogens: A Novel Approach. Nanomaterials 2020, 10, 1457. [CrossRef]

10. Chae, H.H.; Kim, B.-H.; Yang, K.S.; Rhee, J.I. Synthesis and antibacterial performance of size-tunable silver nanoparticles with electrospun nanofiber composites. Synth. Met. 2011, 161, 2124-2128. [CrossRef]

11. Panáček, A.; Kvítek, L.; Prucek, R.; Kolář, M.; Večeřová, R.; Pizúrová, N.; Sharma, V.K.; Nevěčná, T.; Zbořil, R. Silver Colloid Nanoparticles: Synthesis, Characterization, and Their Antibacterial Activity. J. Phys. Chem. B 2006, 110, 16248-16253. [CrossRef]

12. Pal, S.; Tak, Y.K.; Song, J.M. Does the Antibacterial Activity of Silver Nanoparticles Depend on the Shape of the Nanoparticle? A Study of the Gram-Negative Bacterium Escherichia coli. Appl. Environ. Microbiol. 2007, 73, 1712-1720. [CrossRef]

13. Yang, X.; Gondikas, A.P.; Marinakos, S.M.; Auffan, M.; Liu, J.; Hsu-Kim, H.; Meyer, J.N. Mechanism of Silver Nanoparticle Toxicity Is Dependent on Dissolved Silver and Surface Coating inCaenorhabditis elegans. Environ. Sci. Technol. 2011, 46, 1119-1127. [CrossRef]

14. El Badawy, A.M.; Silva, R.G.; Morris, B.; Scheckel, K.G.; Suidan, M.T.; Tolaymat, T.M. Surface Charge-Dependent Toxicity of Silver Nanoparticles. Environ. Sci. Technol. 2011, 45, 283-287. [CrossRef]

15. Gao, P.; Chang, X.; Zhang, D.; Cai, Y.; Chen, G.; Wang, H.; Wang, T.; Kong, T. Synergistic integration of metal nanoclusters and biomolecules as hybrid systems for therapeutic applications. Acta Pharm. Sin. B 2020. [CrossRef]

16. Wang, B.; Zhao, M.; Mehdi, M.; Wang, G.; Gao, P.; Zhang, K.-Q. Biomolecule-assisted synthesis and functionality of metal nanoclusters for biological sensing: A review. Mater. Chem. Front. 2019, 3, 1722-1735. [CrossRef]

17. Luo, Z.; Zheng, K.; Xie, J. Engineering ultrasmall water-soluble gold and silver nanoclusters for biomedical applications. Chem. Commun. 2014, 50, 5143-5155. [CrossRef]

18. Choi, H.; Ko, S.-J.; Choi, Y.; Joo, P.; Kim, T.; Lee, B.R.; Jung, J.-W.; Choi, H.J.; Cha, M.; Jeong, J.-R.; et al. Versatile surface plasmon resonance of carbon-dot-supported silver nanoparticles in polymer optoelectronic devices. Nat. Photon 2013, 7, 732-738. [CrossRef]

19. Jin, J.-C.; Wu, X.-J.; Xu, J.; Wang, B.-B.; Jiang, F.-L.; Liu, Y. Ultrasmall silver nanoclusters: Highly efficient antibacterial activity and their mechanisms. Biomater. Sci. 2016, 5, 247-257. [CrossRef] 
20. Saratale, R.G.; Cho, S.-K.; Saratale, G.D.; Kadam, A.A.; Ghodake, G.S.; Kumar, M.; Bharagava, R.N.; Kumar, G.; Kim, D.S.; Mulla, S.I.; et al. A comprehensive overview and recent advances on polyhydroxyalkanoates (PHA) production using various organic waste streams. Bioresour. Technol. 2021, 325, 124685. [CrossRef]

21. Chao, S.; Li, Y.; Zhao, R.; Zhang, L.; Li, Y.; Wang, C.; Li, X. Synthesis and characterization of tigecycline-loaded sericin/poly (vinyl alcohol) composite fibers via electrospinning as antibacterial wound dressings. J. Drug Deliv. Sci. Technol. 2018, 44, $440-447$. [CrossRef]

22. Zhao, R.; Li, X.; Sun, B.; Zhang, Y.; Zhang, D.; Tang, Z.; Chen, X.; Wang, C. Electrospun chitosan/sericin composite nanofibers with antibacterial property as potential wound dressings. Int. J. Biol. Macromol. 2014, 68, 92-97. [CrossRef]

23. Khan, M.Q.; Kharaghani, D.; Shahzad, A.; Duy, N.P.; Hasegawa, Y.; Lee, J.; Kim, I.S. Fabrication of Antibacterial Nanofibers Composites by Functionalizing the Surface of Cellulose Acetate Nanofibers. ChemistrySelect 2020, 5, 1315-1321. [CrossRef]

24. Mahar, F.K.; He, L.; Wei, K.; Mehdi, M.; Zhu, M.; Gu, J.; Zhang, K.; Khatri, Z.; Kim, I. Rapid adsorption of lead ions using porous carbon nanofibers. Chemosphere 2019, 225, 360-367. [CrossRef]

25. Mehdi, M.; Mahar, F.K.; Qureshi, U.A.; Khatri, M.; Khatri, Z.; Ahmed, F.; Kim, I.S. Preparation of colored recycled polyethylene terephthalate nanofibers from waste bottles: Physicochemical studies. Adv. Polym. Technol. 2018, 37, 2820-2827. [CrossRef]

26. Son, W.K.; Youk, J.H.; Park, W.H. Antimicrobial cellulose acetate nanofibers containing silver nanoparticles. Carbohydr. Polym. 2006, 65, 430-434. [CrossRef]

27. Khatri, M.; Ahmed, F.; Ali, S.; Mehdi, M.; Ullah, S.; Duy-Nam, P.; Khatri, Z.; Kim, I.S. Photosensitive nanofibers for data recording and erasing. J. Text. Inst. 2021, 112, 429-436. [CrossRef]

28. Saquing, C.D.; Manasco, J.L.; Khan, S.A. Electrospun Nanoparticle-Nanofiber Composites via a One-Step Synthesis. Small 2009, 5, 944-951. [CrossRef]

29. Yang, Y.; Zhang, Z.; Wan, M.; Wang, Z.; Zou, X.; Zhao, Y.; Sun, L. A Facile Method for the Fabrication of Silver Nanoparticles Surface Decorated Polyvinyl Alcohol Electrospun Nanofibers and Controllable Antibacterial Activities. Polymers 2020, $12,2486$. [CrossRef]

30. Khalil, K.A.; Fouad, H.; Elsarnagawy, T.; Almajhdi, F.N. Preparation and characterization of electrospun PLGA/silver composite nanofibers for biomedical applications. Int. J. Electrochem. Sci. 2013, 8, 3483-3493.

31. Khatri, M.; Ahmed, F.; Shaikh, I.; Phan, D.-N.; Khan, Q.; Khatri, Z.; Lee, H.; Kim, I.S. Dyeing and characterization of regenerated cellulose nanofibers with vat dyes. Carbohydr. Polym. 2017, 174, 443-449. [CrossRef] [PubMed]

32. Kim, C.H.; Kim, S.Y.; Choi, K.S. Synthesis and Antibacterial Activity of Water-soluble Chitin Derivatives. Polym. Adv. Technol. 1997, 8, 319-325. [CrossRef]

33. Liang, S.; Zhang, G.; Min, J.; Ding, J.; Jiang, X. Synthesis and Antibacterial Testing of Silver/Poly (Ether Amide) Composite Nanofibers with Ultralow Silver Content. J. Nanomater. 2014, 2014, 1-10. [CrossRef]

34. Hussain, N.; Mehdi, M.; Yousif, M.; Ali, A.; Ullah, S.; Siyal, S.H.; Hussain, T.; Kim, I. Synthesis of Highly Conductive Electrospun Recycled Polyethylene Terephthalate Nanofibers Using the Electroless Deposition Method. Nanomaterials 2021, 11, 531. [CrossRef]

35. Jiang, G.-H.; Wang, L.; Chen, T.; Yu, H.-J.; Wang, J.-J. Preparation and characterization of dendritic silver nanoparticles. J. Mater. Sci. 2005, 40, 1681-1683. [CrossRef]

36. Xu, F.; Weng, B.; Materon, L.A.; Kuang, A.; Trujillo, J.A.; Lozano, K. Fabrication of cellulose fine fiber based membranes embedded with silver nanoparticles via Forcespinning. J. Polym. Eng. 2016, 36, 269-278. [CrossRef]

37. Ahmed, F.; Arbab, A.A.; Jatoi, A.W.; Khatri, M.; Memon, N.; Khatri, Z.; Kim, I.S. Ultrasonic-assisted deacetylation of cellulose acetate nanofibers: A rapid method to produce cellulose nanofibers. Ultrason. Sonochem. 2017, 36, 319-325. [CrossRef]

38. Hadipour-Goudarzi, E.; Montazer, M.; Latifi, M.; Aghaji, A.A.G. Electrospinning of chitosan/sericin/PVA nanofibers incorporated with in situ synthesis of nano silver. Carbohydr. Polym. 2014, 113, 231-239. [CrossRef]

39. Islam, M.S.; Yeum, J.H.J.C.; Physicochemical, S.A.; Aspects, E. Electrospun pullulan/poly (vinyl alcohol)/silver hybrid nanofibers: Preparation and property characterization for antibacterial activity. Colloids Surf. A Physicochem. Eng. Asp. 2013, 436, 279-286. [CrossRef] 